\title{
Gastrointestinal helminth parasites of dogs in rural areas of the north east of Algeria
}

\author{
F. Matallah ${ }^{1 *}$, W. Khelaifia ${ }^{1}$, S. Lamari ${ }^{1}$ and S. Matallah ${ }^{2}$ \\ ${ }^{1}$ Department of Veterinary Sciences, ${ }^{2}$ Department of Agronomy, Faculty of Sciences and Life, \\ University Chadli Benjdid, El Tarf. * fouzi_vet16@yahoo.fr
}

(Received November 25, 2017; Accepted January 5, 2018)

\begin{abstract}
Canine faeces are an important source of pathogens for the pet population, for dog owners and for the community in general. A total of 100 faecal samples taken from dogs, were examined for helminth eggs. $80 \%$ of dogs examined are parasitized. Toxocara canis and Ancylostoma caninum were the most commonly observed parasites. T. canis was observed with a prevalence of $68 \%$ in the El Kala region, while in the region of Guelma, A. caninum were predominant with a rate of 71\%. Dipylidium caninum and Trichuris were present but with low proportions especially in the region of Guelma. The climatic conditions seem to play a role in the excretion of helminth eggs, while the age plays a primordial role in particular for $T$. canis as well as for A. caninum. The absence of conscience of the owners of dogs and the lack of participation of the veterinarian' role increase the risk of the parasitism of these animals and consequently for the public health in particular our children in the Northeast of Algeria.
\end{abstract}

Keywords: Dogs, Helminths, Eggs, Coproscopy, Algeria

Available online at http://www.vetmedmosul.org/ijvs

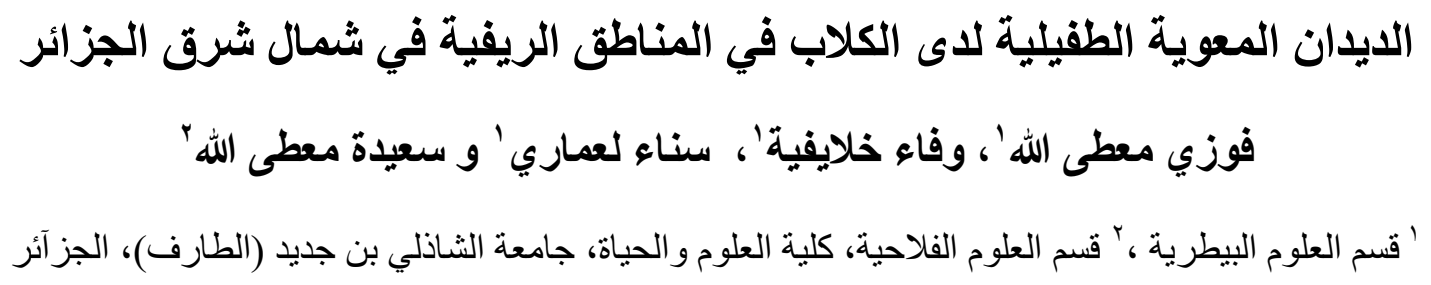

الخلاصة

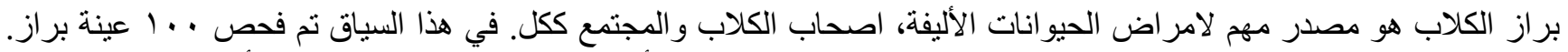

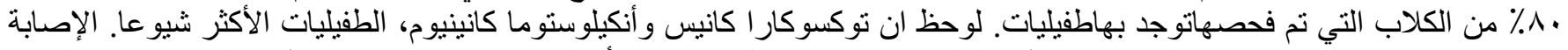

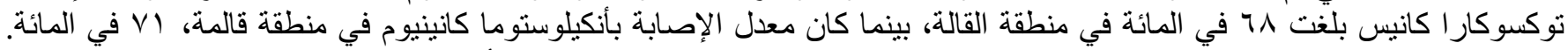

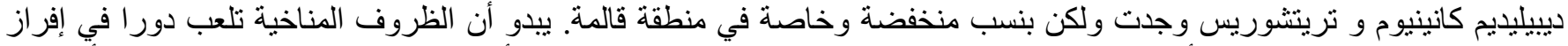

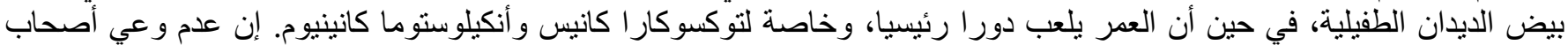

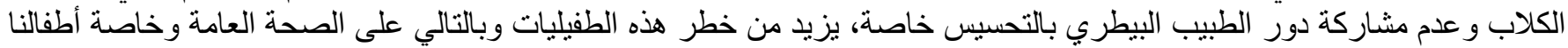

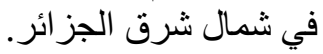

\section{Introduction}

Gastro intestinal helminths are among the most common pathogenic agents encountered in dogs, especially in newly whelped or neonates and they constitute one of the main causes of pathologen of the gastro intestinal tract in dogs (1)

Some of these helminths are responsible for zoonotic diseases such as Toxocariasis and giardiasis (1-3). So, Toxocara canis and Ancylostoma caninum are, respectively, 
the primary species of roundworms and hookworms infecting dogs worldwide (4-6).

Prevalence of digestive parasites is difficult to estimate and different epidemiological surveys show large variations (7). The clinical symptoms of helminth infected dogs depend on the age of animal, the severity of infection, location and developmental stage of the worms. Majority of dogs infected with worms are asymptomatic, however young puppies show clinical signs which include poor growth, potbelly, vomiting, diarrhea, coughing or nasal discharge (8).

There is still inadequate information on these infections in dogs in Algeria. Knowledge of the type of gastrointestinal helminths in dogs in a particular area is important to identify the zoonotic risk in the prevention and control of infections. However and in view of the close association of dog and human beings and the growing trend of breeding of pets, it is necessary to fill this gap in our knowledge, through a study at estimating the prevalence of gastrointestinal helminths in dogs in this locality with special attention to potential zoonotic diseases.

\section{Materials and methods}

\section{Study areas}

The study was conducted in two different bioclimatic areasin the northeastern of Algeria (Guelma and El Kala) (Fig. 1). Guelma is located in the heart of a large agricultural region at $290 \mathrm{~m}$ altitude, far from about $50 \mathrm{~km}$ from the Mediterranean Sea. It is surrounded by mountains (Maouna, Dbegh, and Houara) which give it the name of city plate; its area enjoys great fertility thanks to the Seybouse and a large dam that provides a large irrigation perimeter. The temperature varies from $4^{\circ} \mathrm{C}$ in winter to more than $35^{\circ} \mathrm{C}$ in summer. Rainfall varies from 400 to $500 \mathrm{~mm} /$ year in the South to nearly $1000 \mathrm{~mm} /$ year in the North. About $57 \%$ of this rainfall is recorded during the wet season (October-May). The climate is classified from subhumid to semi-arid. While the coastal area (El-Kala), with a climate strongly marked by the proximity of the sea and is characterized by high humidity and a mild winter temperature (averages of January $>10^{\circ} \mathrm{C}$ ). Average maximum temperatures are high in July-August and exceed $30^{\circ} \mathrm{C}$. An altitude of $1 \mathrm{~m}$ and a humid climate characterize this area.

\section{Animal population}

The local dogs (not standardized) came from villages whose owners were available at the time of sampling. Study was conducted between January and June 2016. The animal population studied consists of 100 dogs of different ages and sexes, distributed equally $(50 \mathrm{dogs})$ in each region. It was mostly puppies that formed the dog population in El Kala while young dogs and adults were examined in the
Guelma area. The animals in question were roaming freely with ruminants. Anthelmintics treatments are not common for their owners. Dogs defecate in the environment without collecting faeces. At night, these dogs take their kennels beside the houses of their owners.

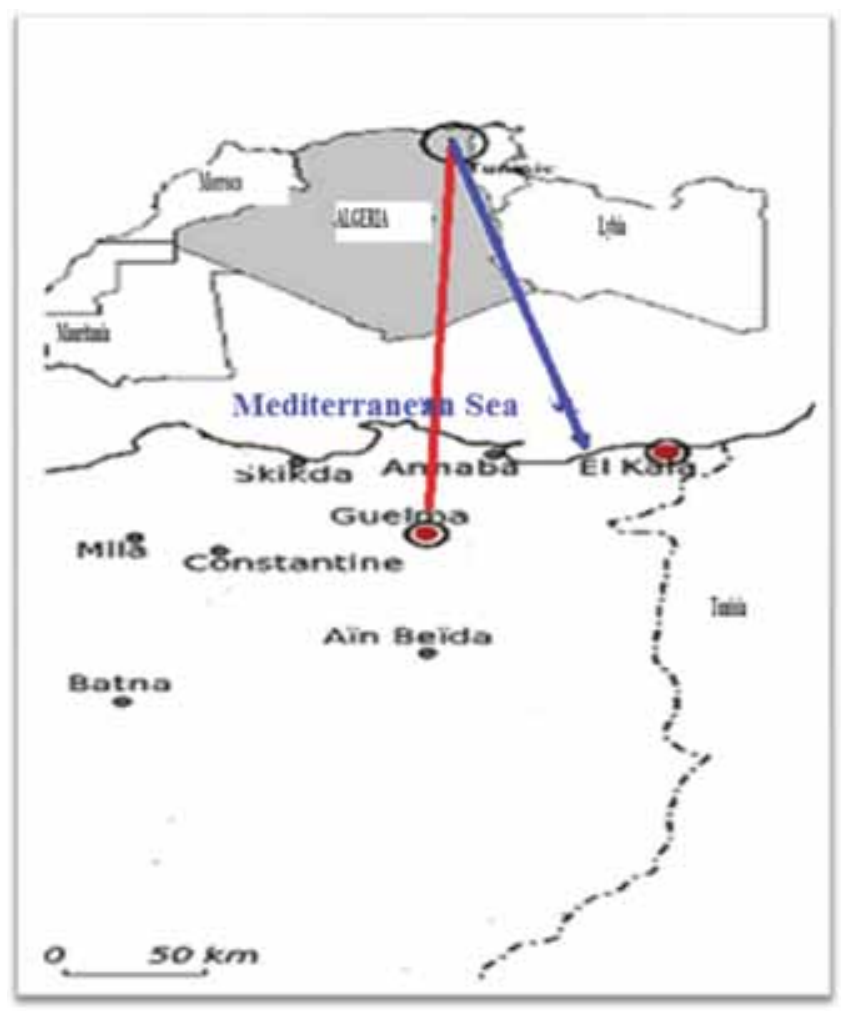

Figure1: Areas of study.

\section{Faecal sample collections and processing}

The faeces samples are kept in plastic containers (forcoproscopy), well identified (age and sex of the dog). Afterwards, we go to the parasitology laboratory for a coprological examination. A clinical exam is done in parallel for each dog to record clinical abnormalities. The coproscopic examination is carried out using the McMASTER method giving both a qualitative and quantitative evaluation of parasitic infection. The results are expressed in number of eggs per gram of feces (OPG). The coproscopy were carried out according to the McMaster method in magnesium sulphate $\left(\mathrm{d}=1.28\right.$ at $\left.25^{\circ} \mathrm{C}\right)$ with a ratio of $5 \mathrm{~g}$ of faeces per $75 \mathrm{ml}$ of solution $(1,2,8,9)$.

\section{Statistical analysis}

For the statistical analysis of the data, the one-way analysis of variance (ANOVA) test was used to determine significance of monthly variations of epg excretion, and variations of epg excretion by sex. The correlation test is used for the age criterion and the excretion of epg. 


\section{Results}

About 80 dogs $/ 100$ are parasitized (Prevalence $=80 \%$ ). The coprological analysis identified us: Toxocara canis, Ancylostoma caninums and Dipylidium caninum in dogs of Guelma then, we found in addition to previous parasites of Trichuris in El Kala area.

The number of epg of $T$. canis is higher of the parasitism in El Kala with 68\% (7900 epg / total of 11550 epg). In Guelma, we recorded 6275 epg, representing $27 \%$ of the parasitic population of this area.

On the contrary, A. caninum come first in Guelma with a remarkable rate of $71 \%(16725 \mathrm{epg} /$ total of $23450 \mathrm{epg})$. This parasitic species was in second place in the El Kala region with a $17 \%$ (1975) rate of parasite total.

The eggs of Trichuris were present only in dogs at the area of El Kala with a small amount (450 epg) (Prevalence $=4 \%)$. Also, D. caninum is observed with $1225 \mathrm{epg}$ (Prevalence $=11 \%$ ). Whereas it is just a total of $450 \mathrm{epg}$ that was found in Guelma (2\%).
Monthly variations of epg excretion in both study are not significant $(\mathrm{P}=0.708>5 \%)$. The age criterion is very important and especially involved for T. canis in El Kala whose puppies raised high numbers of epg. While the number of epg of $A$. caninumwas very high in young $\operatorname{dogs}$ and adults in the region of Guelma. A positive correlation is calculated between the number of epg and the age factor ( $r$ $=1$ ) in El Kala and Guelma areas. Also, males are more parasitized than females in both study areas (no significant differences $\mathrm{P}>0.05$ ).

A poly parasitism is observed in $50 \%$ of the canine population in Guelma, while that in El Kala is raised to $64 \%$.

The Clinical examination of dogs revealed the following symptoms: diarrhea (20\%), hair loss (15\%), and paleness of the mucous membranes $(25 \%)$. Weight loss is the common clinical sign for all dogs $(100 \%)$.

Table 1: Results of eggs excretion in dogs (El Kala, Guelma)

\begin{tabular}{|c|c|c|c|c|c|c|c|c|c|}
\hline \multirow[t]{3}{*}{ Age (mounth) } & & \multicolumn{8}{|c|}{ Helminth (EPG) } \\
\hline & & \multicolumn{2}{|c|}{ T. canis } & \multicolumn{2}{|c|}{ A. caninum } & \multicolumn{2}{|c|}{ D. caninum } & \multicolumn{2}{|c|}{ Tricuris } \\
\hline & & $E$ & $G$ & $E$ & $G$ & $E$ & $G$ & $E$ & $G$ \\
\hline$<12$ & & 6000 & 2500 & 275 & 725 & 700 & 250 & 175 & I \\
\hline $\mathrm{Nb}=30$ & $\mathrm{Nb}=8$ & & & & & & & & \\
\hline $\mathrm{Nbi}=26(87 \%)$ & $\mathrm{Nbi}=4(50 \%)$ & & & & & & & & \\
\hline $13-24$ & & 900 & 2500 & 850 & 6000 & 275 & 100 & 175 & l \\
\hline $\mathrm{Nb}=10$ & $\mathrm{Nb}=20$ & & & & & & & & \\
\hline $\mathrm{Nbi}=6(60 \%)$ & $\mathrm{Nbi}=14(70 \%)$ & & & & & & & & \\
\hline $25-36$ & & 600 & 775 & 400 & 5000 & 150 & 100 & 100 & l \\
\hline $\mathrm{Nb}=8$ & $\mathrm{Nb}=8$ & & & & & & & & \\
\hline $\mathrm{Nbi}=6(75 \%)$ & $\mathrm{Nbi}=8(100 \%)$ & & & & & & & & \\
\hline$>37$ & & 400 & 500 & 450 & 5000 & l & l & l & l \\
\hline $\mathrm{Nb}=2$ & $\mathrm{Nb}=14$ & & & & & & & & \\
\hline $\mathrm{Nbi}=2(100 \%)$ & $\mathrm{Nbi}=14(100 \%)$ & & & & & & & & \\
\hline
\end{tabular}

Nb: Number of dogs, Nbi: Number of infested dogs, EPG: Eggs per gram, T: Toxocara, A: .Ancylostoma, D: Dipylidium, E: El Kala, G: Guelma, \%: Infestation rate.

\section{Discussion}

The use of McMaster egg counting method is justified by the fact that this technique has a good sensitivity. In addition; this method also makes it possible to highlight small, light, predominant eggs in dog faeces, unlike sedimentation methods. Also, our epidemiological survey could be conducted with research of quantitative results (79).

Variations were shown between carnivore infection rates in rural areas between the two study areas. The high prevalence obtained in this survey is mainly for $A$. caninum and $T$. canis. Prevalence of parasitism is higher in comparison with previous work in Nigeria (68\%) (10) and Ghana $(62.6 \%)(11)$. it is slightly lower than that reported in Mexico (85\%) (12). As a result, many conditions (climatic and environmental) in these countries, particularly in Africa (13), are conducive to the development, survival and transmission of infectious stages of parasites, mainly by contributing to the $34 \%$ prevalence reported in Europe $(14,15)$ and $36 \%$ reported in the United States $(6)$.

The number of the epgof intestinal helminthic parasites per revealed host showed that the single infestation was less frequent, and poly parasitism was detected with high rates 
in both regions. Our results do not agree with the results of other studies $(2,3,16)$. While (17) explained that interactions between parasite species depend on parasite burden rather than the presence of other species. (18) have suggested that two or more parasites would only occur in a host if they are not competing if they or have different physiological needs.

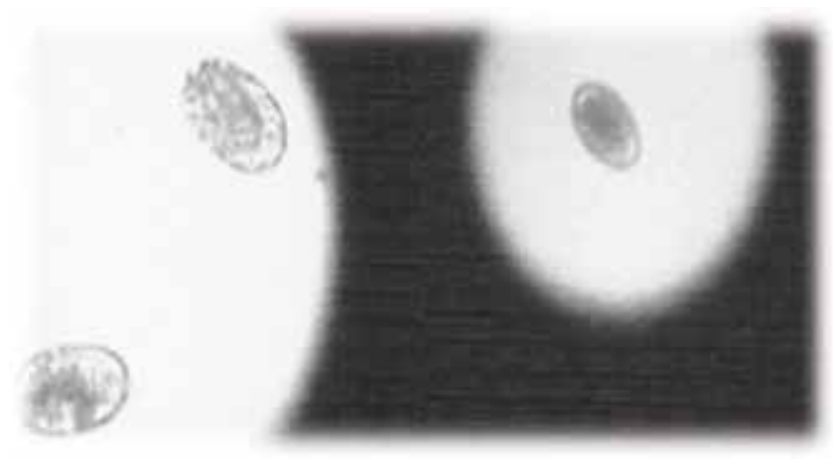

A. caninum

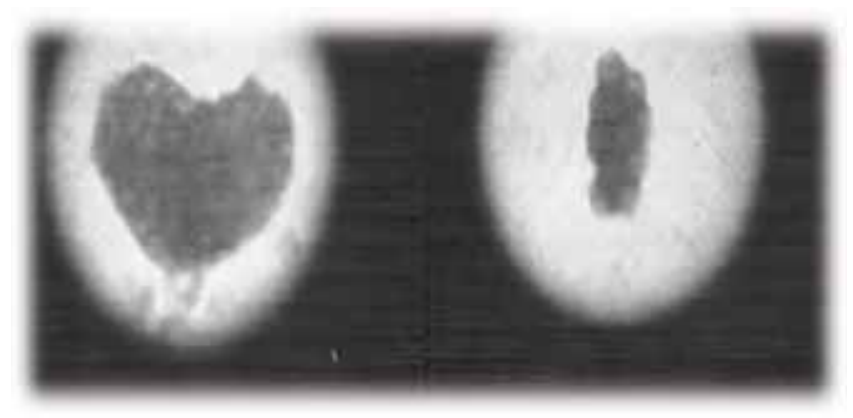

D. caninum

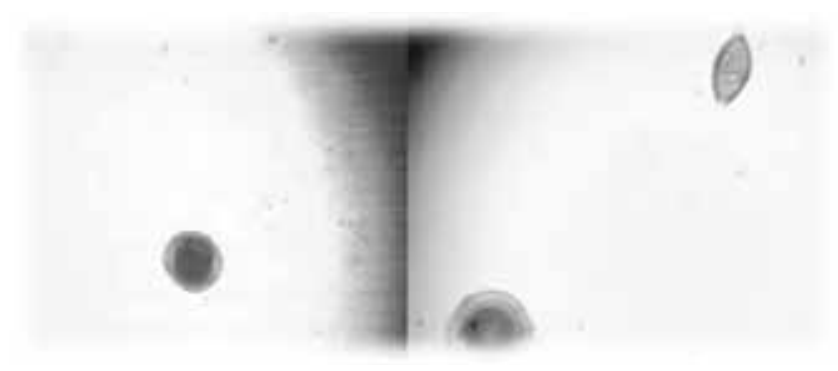

T. canis and Trichuris

Figure 2: (Original). Helminthic species (X10).

It is important to note the high observed rate of $T$. canis / A. caninum combination and the low rates of their separate combination with other species determine the affinity of this combination? The answers to these questions are essential for a good understanding of the epidemiology and control of these diseases (6).

\section{Toxocara canis}

A prevalence of $72 \%$ for $T$. canis in El Kala shows the essential role of climatic factors for the development of this parasitic species. Similarly, Ascarid eggs have an optimal development between $15{ }^{\circ} \mathrm{C}$ and $30{ }^{\circ} \mathrm{C}$ and between $80 \%$ and $90 \%$ moisture which makes this area a favorable environment for parasite development (19). The area of Guelma also by sub humid climate is also favorable for this parasitic species. The importance of the age factor is significantly demonstrated, especially in El Kala area (a majority of puppies), with regard to helminth infestations $(20,21)$. Various surveys conducted worldwide indicate that prevalence of Toxocara infection in canid definitive hosts ranged from $86-100 \%$ in puppies and $1-45 \%$ in adult dogs $(11,12,14,16,17,19,20,22,23)$. This finding is related to the evolutionary cycles of parasites and the risk of infestation. This is consistent with other studies that have reported similar results $(5,6,24)$. The prevalence of ascariasis infections in puppies is consistent with the transmission pattern of the parasite which is predominantly by transplacental and transmammary pathways in the early days of puppy life which increase the occurrence of the parasite at an early age $(21,25)$.

\section{Ancylostoma caninum}

Ancylostoma infection is directly dependent on the ecology of free larval stages, which require a moist and sufficiently hot soil, and the frequency of cutaneous contact with these L3s (barefoot, agricultural work) $(26,27)$. The air currents entering the region of Guelma makes it a Mediterranean climate favoring the maturation, then the survival of the infesting elements (eggs or larvae of helminths).It is characterized by constant and high temperatures, a hygrometry always important (Climate subhumid to semi-arid) with an abundance of rains. The area of Guelma ensures by their climatological characters a favorable environment for the development of this parasite which explains the large number of epg. The nature and texture of soils have a direct influence on the survival of eggs and larvae in the outdoor environment. Thus, wet and shady (rural) soils are more favorable to the multiplication of the parasite than concrete soils cleaned daily of their droppings. Dogs in our villages are therefore particularly vulnerable to parasitism. The study shows, as in other studies conducted on these parasites, that the affected animals are mainly young dogs.Indeed, this corresponds to the animal population of Guelma (7). This high rate of infestation in this age group is explained, in particular, by the low immunity developed by the young dogs, as well as by the small thickness of their skin favorable to the penetration of the larvae of Ancylostoma.Also, in our 
survey, infected dogs lived in an outdoor environment and had access to the forest environment and may have become contaminated with fecal matter from wild animals (28).

\section{Dipylidium caninum and Trichuris}

We recorded a low prevalence of D.caninum (4\% and 2 $\%$ for El Kala and Guelma, respectively). This result is in line with what has been reported in Africa $(11,24,29)$. Also, in our investigation, infested dogs lived in an outdoor environment and had access to the forest environment and may have become contaminated with fecal matter from wild animals. Some Authors $(3,30)$ indicated that necropsy provides more detailed information. However, we could not perform necropsy in this study because dogs could not be killed for such purposes. $D$. caninum a zoonotic tapeworm of which human is an occasional host.The presence of this parasite in study areas is important for public health, especially for children who are more likely to be infected with dipylidase than adults (31). The eggs of the Trichuris are naturally more common in adult dogs because the infection is done in the external environment, by ingestion of extremely resistant eggs. This may explain the low number of epg by this parasitic species in our study whose dogs are mostly young (32). Comparing with other results such as the study by (8) in Maracaibo, Venezuela, seven species of helminths were reported from 614 dogs examined, another study in Ibadan, Nigeria (33), six species of helminths have been reported in 959 dogs examined and in Spain (Cordoba) (30) with 300 dogs, we can say that the low number of helminth specimens found may be due to the decrease in the number of dogs ( 100 dogs $)$ examined in our study.

Finally and concerning the symptoms identified during the examination of the dogs, we recorded in addition to the general weakness (slimming) of dogs, a diarrhea, a paleness of the mucous membrane and hair loss.Our results are in accord with (20) whom reported that the majority $(71.72 \%)$ of the 244 infected dogs showed no clinical signs and the Anemia, weakness and diarrhea were evident in $16.80 \%$, $11.40 \%$, and $10.25 \%$, of dogs respectively. The first indication of T. canis infection in young animals is retarded growth and weight loss, a dull coat and often a pot-bellied appearance, vomiting, diarrhea, $(23,27,34)$. As other authors have noted, a large number of $A$. caninum infections in pups or young dogs can cause acute or peracute disease, with bloody or black diarrhea, anaemia and depression (34). By contribution to these results, we can say the hair loss $(15 \%)$ reinforces these results, especially for $T$. canis infestation and the presence of diarrhea leads us to diagnose towards infestations by hookworms.

\section{Conclusion}

The present study has detected the high prevalence of gastrointestinal helminths identified in Northeastern of Algeria: T. canis, A. caninum and to a lesser degree $D$. caninum, which are zoonotic constituting a public health problems. In this sense, a larger study with a larger number would be essential to clarify the situation of the internal parasitism of our dogs. The control of the environment is also very important. To reduce the risk of contamination, the stool must be collected and destroyed. Finally, intervention measures are necessary to reduce the risk of transmission of parasites from dogs to humans due to lack of veterinary control.

\section{References}

1. Anteson RK, d Corkish JD. An investigation of helminth parasites in well-cared for dogs in Accra," Ghana Medical Journal. 1975; 14( 3): 193-195.

2. Akao N, Ohta N. Toxocariasis in Japan. Parasitol Int. 2007; 56:87-93.

3. Zewdu E., Semahegn Y., and Mekibib B. "Prevalence of helminth parasites of dogs and owners awareness about zoonotic parasites in Ambo town, central Ethiopia," Ethiopian Vet J. 2010;14(2):17-30.

4. Beugnet, F., Edderai, D. Enquête sur les helminthes parasites digestifs et sanguins chez les chiens à Libreville, Gabon. Revue de Médecine Vétérinaire. $1998 ; 149: 327-330$.

5. Bowman D.D. Georgi's Parasitology for Veterinarians. 9th edition. Philadelphia, USA: Saunders Company.2009.

6. Soulsby EJL. (1982). Helminths, Arthropods and Protozoa of Domesticated Animals. 7th edition. London, UK: Bailliere Tindall.1989.

7. Beugnet $F$. Helminthoses digestives et choix des vermifuges chez les carnivores. L'Action Vétérinaire. 1998;1436:33-44.

8. Ramirez-Barrios RA, Barboza-Mena G, Munoz J, Angulo-Cubillan F, Hernandez E. Prevalence of intestinal parasites in dogs under veterinary care in Maracaibo, Venezuela. Vet Parasitol. 2004;121:1120.

9. Blagburn BL, Lindsay DS, Vaughan JL, Rippey NS, Wright JC, et al. Prevalence of canine parasites based on fecal flotation. Compen Conti EducPract Veter. 1996;18: 483-509.

10. Papa Kofi Amissah-Reynolds,1 Isaac Monney,2 Lucy Mawusi Adowah,1 and Samuel Opoku Agyemang1. Prevalence of Helminths in Dogs and Owners' Awareness of Zoonotic Diseases in Mampong, Ashanti, Ghana. J Parasitol Res. 2016; Article ID 1715924, 6 pages.

11. Johnson SAM, Gakuya DW, Mbuthia PG, Mande JD, Maingi N. (2015). Prevalence of gastrointestinal helminths and management practices for dogs in the Greater Accra region of Ghana. Heliyon 1: e00023. Journal of Parasitology Research Volume 2016. 2015; Article ID 1715924, 6 pages http://dx.doi.org/10.1155/2016/1715924

12. Eguía-Aguilar P, Cruz-Reyes A, Martínez-Maya JJ.Ecological analysis and description of the intestinal helminths present in dogs in Mexico City. Vet Parasitol. 2005;127:139-146.

13. Ugbomoiko US, Ariza L, Heukelbach J. Parasites of importance for human health in Nigerian dogs: high prevalence and limited knowledge of pet owners. BMC Vet Res. 2008;4: 49.

14. Habluetzel $A^{1}$, Traldi G, Ruggieri S, Attili AR, Scuppa P, Marchetti R, Menghini G, Esposito F. An estimation of Toxocaracanis prevalence in dogs, environmental egg contamination and risk of human infection in the Marche region of Italy. Vet Parasitol. 2003; $113(3-4): 243-52$.

15. Overgaauw PA. Prevalence of intestinal nematodes of dogs and cats in The Netherlands. Vet Q. 1997;19:14-17. 
16. Donato Traversa $1^{*}$, Antonio Frangipane di Regalbono2, Angela Di Cesare1, Francesco La Torre3, Jason Drake4 and Mario Pietrobelli2 Traversa et al. Parasites \& Vectors. 2014; 7:67 http://www.parasitesandvectors.com/content/7/1/67.

17. Fontanarrosa MF, Vezzani D, Basabe J, Eiras DF. An epidemiological study of gastrointestinal parasites of dogs from Southern Greater Buenos Aires (Argentina): Age, gender, breed, mixed infections, and seasonal and spatial patterns. Vet Parasitol. 2006;136: 283-295.

18. Schmidt GD, Roberts LS. Foundation of Parasitology. Toronto, Times Mirror/Mosby College Publishers.1989.

19. Gevrey J. Ankyslo-stomidoses des carnivores domestiques. Rec Méd Vét 1993; 169, 345-351

20. Lefkaditis1 MA, Koukeri2 E.S. and Cozma V. 2 1. Symptoms associated with intestinal ascaridida and strongylida infections in dogs. Revue Méd Vét.2006;157( 5): 270-271.

21. Magnaval JF, Glickman LT, Dorchies P. La toxocarose, une zoonose helminthique majeure. Rev Méd Vét.1994;145 (8-9):611-627.

22. Daryani A, Sharif M, Amouei A, Gholami S. Prevalence of Toxocaracanis in stray dogs, northern Iran. See comment in PubMed Commons below Pak J BiolSci.2009; 12:1031-1035.

23. Georgi J.R., Theodorides V. J.Parasitology for Veterinarians. Edited by W.B. Saunders Company, Philadelphia.1985.

24. Okoye IC, Obiezue NR, Okorie CE, Ofoezie IE. Epidemiology of gastrointestinal helminth parasites of stray dogs in Obollo-Afor and Ekwulobia markets, Southeast Nigeria. J Helminthol. 2011;85:415420 .
25. Pereckiene A, Kazi̊̊«naite V, Vysniauskas A, Petkevicius S, Malakauskas A, et al. A comparison of modifications of the McMaster method for the numeration of Ascarissuum eggs in pig faecal samples. Vet Parasitol. 2007; 149: 111-116

26. Beugnet F. Le parasitisme digestif des carnivores domestiques importance des protozooses. L'Action Vétérinaire. 1998;1453:12-18.

27. Anderson R.C. Nematode Parasites of Vertebrates. Publishing, CAB International. 2000.

28. Samuel WM, Pybus MJ, Kocan AA. Parasitic diseases of wild mammals. Iowa State University Press. Can Vet J. 2001; 43:130.

29. Othman RA. Prevalence of Toxocaracanis in dogs, North West Bank of Palestine. Korean J Parasitol. 2011 49:181-182.

30. Martinez-Moreno FJ, Hernandez S, Lopez-Cobos E, Becerra C, Acosta I,et al. Estimation of canine intestinal parasites in Cordoba (Spain) and their risk to public health. Vet Parasitol. 143: 7-13.

31. Molina CP, Ogburn J, Adegboyega P. Infection by Dipylidiumcaninum in an infant. Arch Pathol Lab Med. 2003;127:157-159.

32. Bourdeau P. Les trichuroses des carnivores. Rec. Méd. Vét. 1993; 169:379-385

33. Sowemimo OA, Asaolu SO. Epidemiology of intestinal helminth parasites of dogs in Ibadan, Nigeria. J Helminthol. 2008; 82: 89-93.

34. Chandler E. A., Thompson D. J., Sutton J. B. Price C. J. 2000. Canine Medecine and Therapeutics, Blackwell Science Ltd.1991. 